There personal contact was likely to end, leaving one unaware that there are over 500 species of pycnogonids contained in eight very distinct families. Their major environment is the deep ocean floor. Over the oozes which cover this they walk on stilt-like legs while direct development from large yolky eggs frees them from dependence on planktonic larvae.

Nor are the legs always confined to four pairs. As far back as 1835 the American zoologist Eights described specimens with greater numbers but these were dismissed as curiosities until later South Polar expeditions dredged both decapodous and dodecapodous species within three distinct families.

In these days students hear little more than passing mention, if even that, of pycnogonids. It is well that the substance of what is known about them should be so ably described and clearly illustrated by P. E. King in this latest volume on marine biology from Hutchinson. It can be strongly recommended to all who work in the sea, indeed will bring enlightenment to all zoologists.

C. M. Yonge

\section{Gonad Anatomy}

Postnatal Development of the Ovary in Homo sapiens and Macaca mulatta and Induction of Ovulation in the Macaque. By Gertrude van Wagenen and Miriam C. Simpson. Pp. 306 (122 plates). (Yale University Press: New Haven, Connecticut and London, 1973.) $£ 11.75$.

THIS book by two eminent researchers in the field is a sequel to an earlier volume by the same authors entitled Embryology of the Ovary and Testis: Homo sapiens and Macaca mulatta. Like its predecessor, the present volume contains over four hundred photomicrographs of excellent quality which illustrate changes in the microanatomy of the ovary during the period from birth to senescence. The legends to the illustrations are largely self-explicit without referring to the text, although some appear to convey a different interpretation. Thus an inspection of the illustrations without reference to the text would give the unwary reader the impression that germ cells are formed throughout juvenile life from within epithelial cords derived from the somatic (so-called germinal) epithelium, when in fact the authors eventually come firmly to the conclusion that this is not the case (see below).

Only a small part of the sixty pages of text and tabular material is actually concerned with the subject given as the title on the cover of the book (four pages on human ovary; twelve for monkey). This section consists of a concise account of structural changes affecting the coelomic epithelium, follicles and stroma, as well as the differen- tiation of germ cells. As such it forms a useful extension to the information conveyed in the first volume in the series. However, in some ways the text is disappointing; some of the references to figure numbers are incorrect and the bibliography is inadequate for a book of this type. It is particularly off-putting that the authors continually build the "Aunt Sally" that neoformation of germ cells from somatic components within the ovary continues long after birth, because they eventually present good evidence (and seem themselves to firmly accept the view) that this is not the case. This first section of the text also contains good accounts of changes in the morphology of the corpus luteum with the phases of the menstrual cycle, and on the occurrence of polyovular follicles.

The bulk of the text consists of an account of a whole series of experiments, conducted over many years, on the effects of various gonadotrophic hormones on the ovary of the rhesus monkey. These experiments were performed with the aim of inducing ovulation and the authors discuss the pitfalls of overstimulation resulting in superovulation. It is particularly interesting to those working in the field of oogenesis that the authors show conclusively that the number of primary follicles is not increased following treatment with FSH. It is to be regretted, however, that the amount of hormone injected is sometimes expressed in "rat units" instead of $\mathrm{mg}$ or international units, although this may well reflect the age of some of these studies, many of which have not been published before. Nevertheless, this section of the book will be of value to endocrinologists and reproductive physiologists in providing data for a species about which little information was previously available.

In summary, this book has a number of minor shortcomings but provides a considerable amount of useful information which is not readily available else- where. As an atlas of the developmental microanatomy of the ovary it is unsurpassed and will be a valued possession of all those concerned with the development and endocrinology of the ovary.

T. G. BAKER

\section{Enzyme Mechanisms}

The Study of Enzyme Mechanisms. By Eugene Zeffren and Philip L. Hall. Pp. $x i+284$. (Wiley-Interscience: New York and London, June 1973.) £7.50.

ThIs book attempts to cover a wide range of topics related to the study of the mechanism of enzymatic catalysis. As well as a series of accounts of enzymes for which plausible mechanisms are available there are sections on purification, chemical modification, kinetics, coenzymes and allosterism. In order to cover such a wide range of topics in a relatively short book the authors have had to be selective in their choice of material. The section on enzyme purification omits any detailed discussion of a number of methods that are in common use and the chapter on the mechanisms of oxidoreductase is restricted to theories which involve proton transfer. In some cases the authors have oversimplified the situation. This is particularly evident in the chapters on kinetics, which only deal with enzymes that have a single substrate, and in the chapter on allosterism, which only considers the theory of Monod, Wyman and Changeux with the more general theory of Koshland mentioned only parenthetically as being "some variation of it". There are very few errors in the book but the chapter on the kinetics of enzyme inhibition contains some misleading information in which steady-state and equilibrium conditions are not sufficiently distinguished and in which mixed and partially noncompetitive inhibition are confused.

The strongest feature of the book is the series of chapters directly concerned with enzyme mechanisms. These com-

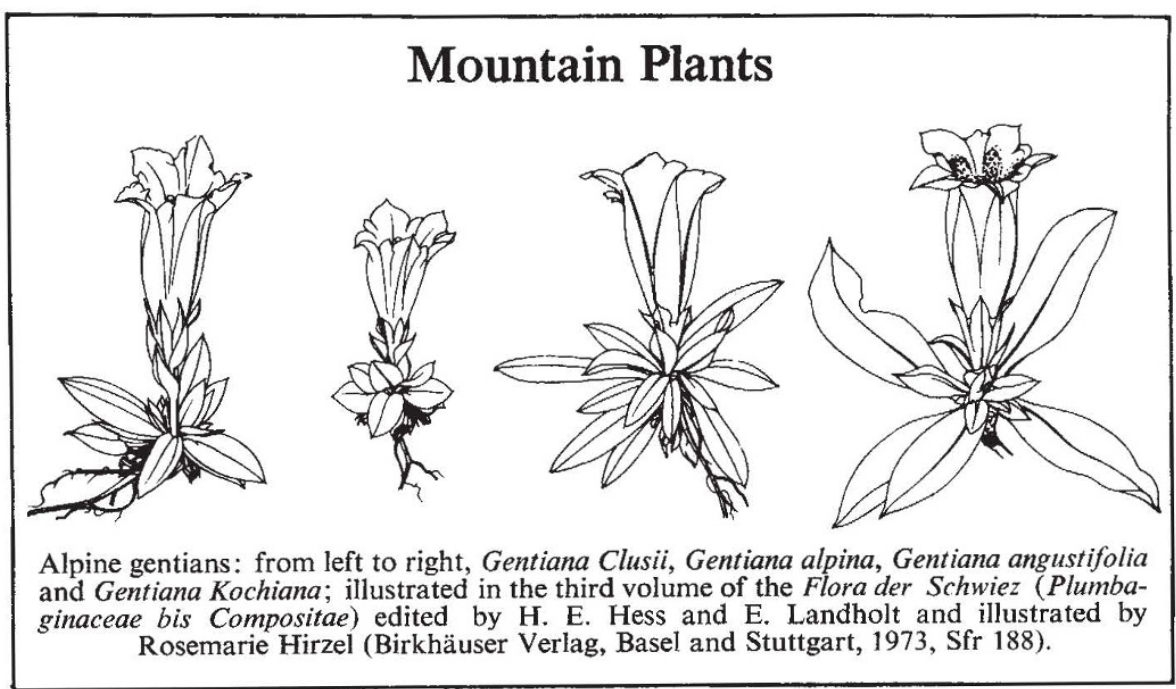

